\title{
Chemotactic Responses of Fibroblasts to Tropoelastin and Elastin-derived Peptides
}

\author{
Robert M. Senior, Gail L. Griffin, and Robert P. Mecham, Pulmonaty Disease \\ and Respiratory Care Division, Department of Medicine, \\ Washington University School of Medicine at The Jewish Hospital \\ of St. Louis, Missouri 63110
}

A B S T R A C T Fibroblasts are known to have chemotactic responses to two components of the extracellular matrix, collagen and fibronectin. To extend these observations to other extracellular connective tissue macromolecules and their proteolytic fragments, fibroblasts from adult human skin and from late-gestation $(270 \mathrm{~d})$, fetal bovine ligaments were studied for chemotactic responsiveness to tropoelastin and elastin-derived peptides. Bovine ligament tropoelastin and elastin-derived peptides, generated from either human aortic elastin with human neutrophil elastase or from bovine ligament elastin with pancreatic elastase, elicited chemotactic responses that were maximal at 0.2 $\mu \mathrm{g} / \mathrm{ml}\left(3 \times 10^{-9} \mathrm{M}\right)$ and $0.5-2.0 \mu \mathrm{g}$ protein $/ \mathrm{ml}$, respectively. Fractionation of the elastin-derived peptides by gel filtration (Bio-Gel P-10) indicated that comparable levels of chemotactic activity were present in all fractions, and amino acid analysis of the fractions showed no relationship between chemotactic activity and desmosine concentration. Taken in conjunction with the observations on tropoelastin, it appears that fibroblast chemotaxis to elastin components does not involve the cross-links of elastin. These results demonstrate that the influences of the connective tissue matrix upon fibroblast migration might include elastin precursors and fragments of elastin.

\section{INTRODUCTION}

Recent evidence indicates that fibroblasts have the capacity to demonstrate chemotaxis. Thus far a variety of chemoattractants for fibroblasts have been identified including lymphokines, collagen, collagen-derived peptides, a complement-related component, fibronectin, and fibronectin-derived peptides (1-8).

Received for publication 22 December 1981 and in revised form 27 April 1982.
The chemotactic responsiveness of fibroblasts to collagen and fibronectin suggests that the extracellular matrix may influence migratory responses of fibroblasts in vivo. The findings also raise the possibility that other constituents of the extracellular matrix have chemotactic activity for fibroblasts. In this study we report that tropoelastin and elastin-derived peptides have the capacity to produce chemotactic responses in fibroblasts.

\section{METHODS}

\section{Fibroblasts}

Fibroblasts were obtained from explants of normal adult skin surgical specimens and from nuchal ligaments of fetal calves at 270-d gestation, as described (9). The cells were cultured in Dulbecco's modified Eagle's medium (DMEM) ${ }^{1}$ obtained from The Center for Basic Cancer Research, Washington University School of Medicine, St. Louis, MO, supplemented with L-glutamine, $2 \mathrm{mM}$, nonessential amino acids, and 10\% fetal bovine serum (KC Biological, Inc., Lenexa, KS). The cells were confluent at two to six (ligament) and six (skin) passages when used. To harvest the cells, the culture medium was poured out, the cells were washed gently with phosphate-buffered saline (PBS), and then detached by addition of a mixture of $\mathbf{0 . 2 5 \%}$ trypsin (Sigma Chemical Co., St. Louis, MO), and 1\% (wt/vol) EDTA in PBS for $3 \mathrm{~min}$ at $37^{\circ} \mathrm{C}$. The cell suspension was promptly diluted into $5 \mathrm{vol}$ of DMEM containing $10 \%$ fetal bovine serum supplemented with $2 \mathrm{mM}$ L-glutamine, and nonessential amino acids. The suspension was centrifuged for $10 \mathrm{~min}$ at $200 \mathrm{~g}, 4^{\circ} \mathrm{C}$, and then the cells were resuspended in DMEM with $2 \%$ (vol/vol) human serum albumin (American Red Cross Blood Services, Wash., DC), glutamine, and nonessential amino acids. The cycle of centrifugation and resuspension of the cells was repeated once, after which the cells were adjusted to 1.2 $\times 10^{5} / \mathrm{ml}$.

${ }^{1}$ Abbreviations used in this paper: DMEM, Dulbecco's modified Eagle's medium; hpf, high power field; PBS, phosphate-buffered saline. 


\section{Chemotactic factors}

Tropoelastin. To obtain pure tropoelastin, minces of bovine ligamentum nuchae were incubated overnight at $37^{\circ} \mathrm{C}$ with DMEM containing 5\% fetal bovine serum, nonessential amino acids, penicillin $(100 \mathrm{U} / \mathrm{ml})$, streptomycin $(100 \mu \mathrm{g} /$ $\mathrm{ml})$, and aminoacetonitrile $(100 \mu \mathrm{g} / \mathrm{ml})$. At the end of the incubation period, the tissue minces were washed extensively with ice-cold water and homogenized using a Polytron (Brinkmann Instruments, Inc., Westbury, NY) at high speed in $0.5 \mathrm{~N}$ acetic acid containing $1 \mu \mathrm{g} / \mathrm{ml}$ pepstatin (Sigma Chemical Co.). The homogenate was stirred overnight at $4^{\circ} \mathrm{C}$ and insoluble material removed by centrifugation $\left(10,000 \mathrm{~g}, 120 \mathrm{~min}, 4^{\circ} \mathrm{C}\right)$. The supernatant was dialyzed 2 d at $4^{\circ} \mathrm{C}$ against 4 liter of $0.01 \mathrm{~N}$ acetic acid. Precipitated material that formed during dialysis was removed by centrifugation and the supernatant was chromatographed on DEAE-cellulose as described (10). Sodium dodecyl sulfatepolyacrylamide gel electrophoresis showed a single band corresponding to a mol wt of 70,000. The amino acid composition (Beckman, 119C amino acid analyser, Beckman Instruments, Inc., Fullerton, CA) was characteristic of purified tropoelastin (11).

Elastin-derived peptides. Using procedures we have reported (12), human aortic elastin was digested with human neutrophil elastase, and then the digest was separated from the elastase by affinity chromatography using Trasylol-Sepharose. Bovine ligament elastin was solubilized with porcine pancreatic elastase as follows: $600 \mathrm{mg}$ of ligament elastin was added to $11 \mathrm{ml}$ of a solution containing $0.1 \%$ (wt/vol) ammonium bicarbonate, $\mathrm{pH} 7.8$, and $4 \mathrm{mg}$ porcine pancreatic elastase. The elastin and elastase were obtained from Elastin Products Co., St. Louis, MO. After incubation $\left(37^{\circ} \mathrm{C}\right.$, $24 \mathrm{~h})>90 \%$ of the elastase activity in the starting reaction mixture was removed from the digest by affinity absorption using elastin as follows: $1.5 \mathrm{~g}$ of coarse-mesh elastin was added to the elastin-elastase digest and gently stirred for 15 min at room temperature. The digested elastin was then separated from the insoluble elastin by centrifugation. To enhance removal of the elastase, this procedure was repeated sequentially five times with fresh coarse-mesh elastin each time and the soluble product was assayed for elastolytic activity using a ${ }^{14} \mathrm{C}$-labeled elastin substrate (13). The composition of the final elastin digest to be used for assays of chemotactic activity was typical of bovine elastin as determined by amino acid analysis. Pancreatic elastase at the concentration in the elastin digests $(<3 \mathrm{ng} / \mathrm{ml})$ had no effect on fibroblast migration.

Gel filtration chromatography of elastin digests. After removal of pancreatic elastase, the bovine ligament elastin digest was applied to a column $(2.5 \times 27 \mathrm{~cm})$ of Bio-Gel P10 (Bio-Rad Laboratories, Richmond, CA), eluted with ammonium bicarbonate, $1 \mathrm{~g} /$ liter, $\mathrm{pH} 7.8$, at $100 \mathrm{ml} / \mathrm{h}$, and collected in 2.4-ml fractions. The fractions were measured for absorbance at $230 \mathrm{~nm}$ (Beckman DU 8 spectrophotometer, Beckman Instruments, Inc.), and protein concentration was determined by amino acid analysis using a program for resolving cross-links of elastin (14).

Fibronectin. Fibronectin purified from human plasma (15) was a gift from Dr. John A. McDonald, Washington University School of Medicine at The Jewish Hospital of St. Louis. The concentration of fibronectin was determined from the extinction coefficient of 1.28 at $280 \mathrm{~nm}$. Fibronectin $(1 \mu \mathrm{g} / \mathrm{ml})$ was used as a positive control in all experiments after confirming that this concentration produced maximal chemotactic activity $(\sim 40$ cells per high power field [hpf] above background).

\section{Determination of chemotactic activity}

Chemotaxis was determined in a multi-blind well apparatus having 30 wells (16). A double-membrane technique, using a polycarbonate membrane (Nucleopore Corp., Pleasanton, CA) with $8-\mu \mathrm{m}$ pores on top of a cellulose nitrate membrane (Millipore Corp., Bedford, MA) having 0.45- $\mu \mathrm{m}$ pores, was used to separate each well into an upper and lower compartment (17). The lower compartment was filled with $240 \mu \mathrm{l}$ of solution to be assayed, or control medium, then covered with the membranes. In the upper compartment was placed $350 \mu \mathrm{l}$ of cell suspension containing $1.2 \times 10^{5}$ cells $/ \mathrm{ml}$.

To facilitate attachment of fibroblasts to the surface of the membranes the membranes were soaked in $1 \%$ (wt/vol) polyL-lysine hydrobromide, mol wt $>70,000$ (P-1399, Sigma Chemical Co.), in distilled water for $2 \mathrm{~h}$ at room temperature, washed for $2 \mathrm{~h}$ under running cold water, and then air dried (18).

After both compartments of the wells were filled, the chemotaxis apparatus was placed in a humidified incubator at $37^{\circ} \mathrm{C}$ in an atmosphere of $5 \%$ carbon dioxide- $95 \%$ air for 5 h. The apparatus was then disassembled and each membrane pair was removed and stained with hematoxylin. Cell migration was determined under high dry magnification $(\times 400)$ by counting the cells that had moved to the interface between the two membranes and those on the lower membrane. Five fields were counted for each membrane; all experiments were done in triplicate, and the results from each set of three membrane pairs were pooled. Cell migration is expressed as the net number of cells migrated per hpf, that is, the number of cells per hpf minus the number of cells per hpf that migrated in response to control medium. The background cell migration was approximately 20 cells per hpf in all experiments.

\section{RESULTS}

Polylysine-coated membranes and a double-membrane method for the determination of fibroblast chemotaxis. Polylysine coating of membranes before addition of the fibroblasts yielded a monolayer of cells that were adherent and well spread out. Without polylysine coating, cells adhered poorly and remained round. The use of a double membrane for fibroblast chemotaxis greatly facilitated locating the cells that had migrated through the upper membrane. Without the lower membrane the cells on the undersurface of the very thin upper membrane could only be seen with oil immersion, as described by other investigators $(1,5)$.

Chemotactic activity of tropoelastin. Tropoelastin-induced migration of both ligament and skin fibroblasts with a maximum response at $0.2 \mu \mathrm{g} / \mathrm{ml}$ (Fig. 1). The migratory activity, which was greater for the ligament fibroblasts than for the skin fibroblasts, was chemotactic as it required a tropoelastin concentration gradient to occur (Table I).

Chemotactic activity of elastin-derived peptides. Elastin-derived peptides either from bovine ligament or human aorta stimulated the migration of skin and ligament fibroblasts (Fig. 2). The maximum responses 


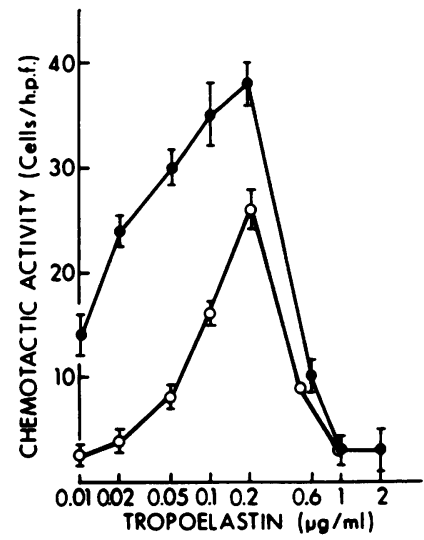

Figure 1 The migration of human skin fibroblasts $(\mathrm{O}-\mathrm{O})$ and bovine ligament fibroblasts $(0-0)$ in response to bovine tropoelastin. Tropoelastin was added to the lower compartments of the assay chambers at the concentrations shown and the net cell migration from the upper compartments was measured as described in Methods (error bars indicate SEM for triplicates)

were observed in the range of $0.5-2 \mu \mathrm{g} / \mathrm{ml}$, peaking at slightly lower concentrations with aortic elastin-derived peptides. With both sources of elastin-derived peptides, human skin fibroblasts showed a lower peak of activity than ligament fibroblasts.

The cell migration to elastin-derived peptides was chemotactic as it could be abolished by putting identical concentrations of elastin digest in both compartments to eliminate a concentration gradient across the membranes (Fig. 3).

Chemotactic activity was detectable in fractions of bovine ligament elastin digest after gel filtration chromatography (Fig. 4). The activity did not show a predominance in any portion of the chromatogram, although relative to the protein concentration the chemotactic activity was greater in fractions corresponding to low $(<14,000)$ molecular weight peptides. The chemotactic activity also did not bear any relation to the desmosine concentrations of the fractions.

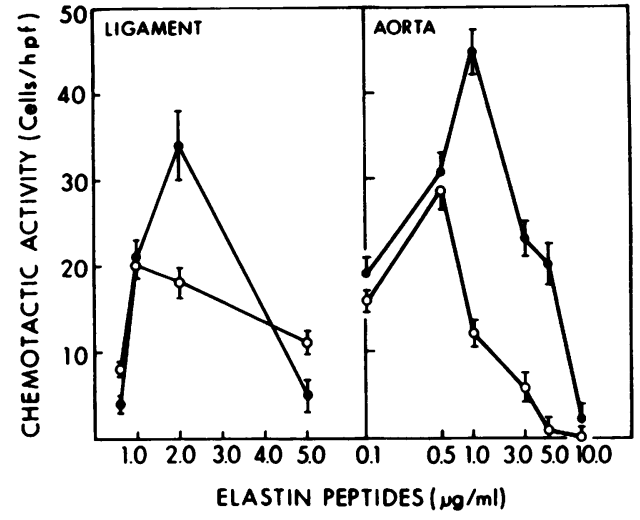

FIGURE 2 The migration of human skin fibroblasts or bovine ligament fibroblasts placed in the upper compartments of assay chambers in response to elastin-derived peptides in the lower compartments: left, bovine ligament elastin-derived peptides; right, human aorta elastin-derived peptides. Data points represent the net mean values of triplicate observations. $O$, skin; $\bullet$, ligament.

\section{DISCUSSION}

These results demonstrate that tropoelastin, the soluble precursor of elastin, and elastin-derived peptides have the capacity to induce fibroblast chemotaxis. Accordingly, as with two other extracellular connective tissue macromolecules, fibronectin and collagen, components of elastin may also influence the migratory activity of fibroblasts $(2,5-8)$.

Previously, we and others reported that human peripheral blood monocytes show chemotaxis to human and bovine elastin-derived peptides $(12,19)$. In those studies the active components of the digested elastin appeared primarily in mixtures of relatively large peptides $(>10,000 \mathrm{~mol} w \mathrm{w})$ that were enriched in desmosine cross-links. Accordingly, it seemed reasonable to conclude that monocyte chemotaxis to elastin products involves lysyl-derived cross-links. This suggestion was supported by the findings of Hunninghake et al. (19) that tropoelastin did not display chemotactic ac-

TABLE I

Fibroblast Chemotactic Activity of Tropoelastin ${ }^{\circ}$

\begin{tabular}{|c|c|c|c|c|c|}
\hline & & \multicolumn{4}{|c|}{ Tropoelastin, upper compartment, $\mathrm{ng} / \mathrm{ml}$} \\
\hline & & 0 & 10 & 50 & 200 \\
\hline \multirow{3}{*}{$\begin{array}{l}\text { Tropoelastin, lower } \\
\text { compartment, } \\
n g / m l\end{array}$} & 10 & $21 \pm 0.5$ & $4 \pm 0.4$ & $1 \pm 0.3$ & $9 \pm 0.4$ \\
\hline & 50 & $32 \pm 0.5$ & $20 \pm 0.6$ & $-1 \pm 0.3$ & $6 \pm 0.4$ \\
\hline & 200 & $48 \pm 1.2$ & $35 \pm 0.7$ & $16 \pm 0.4$ & $6 \pm 0.5$ \\
\hline
\end{tabular}

- Cells $/$ hpf \pm SEM, $n=15$. 


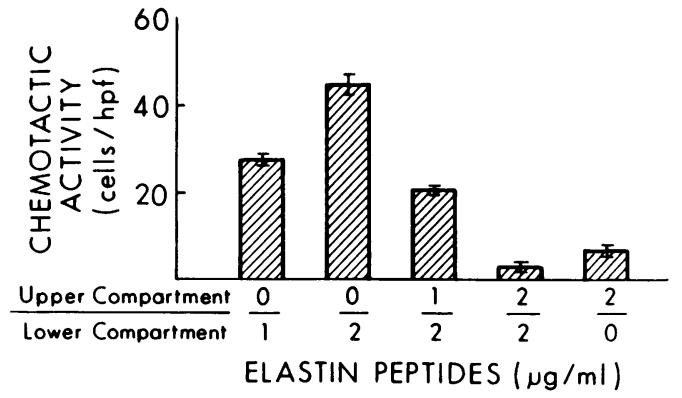

Figure 3 The net migration of bovine ligament fibroblasts, placed in the upper compartment, to bovine elastin-derived peptides. As shown, the elastin peptides were placed in the upper and lower compartments in various combinations to identify the importance of a concentration gradient for cell migration.

tivity. Recently, however, we have observed that tropoelastin, and synthetic peptides with amino acid sequences characteristic of repeating peptides in elastin, (20-23) are chemotactic for human monocytes. ${ }^{2}$ Maximal activity occurs at $\sim 10 \mathrm{nM}$ and is nearly as great as that observed with saturating amounts of chemotactic activity derived from the fifth component of complement. Thus, it appears that cross-links are not necessary for chemotactic activity of elastin peptides.

Our studies were done with fibroblasts from two sources, fetal bovine ligament and adult human skin. Chemotactic responsiveness to tropoelastin and elastinderived peptides by fetal ligament fibroblasts might be expected because these cells are heavily committed to the production of elastin late in fetal life (9). However, because adult human skin fibroblasts, cells that synthesize very little elastin, also showed directed migration to elastin and tropoelastin, it seems likely that fibroblasts generally have such responsiveness.

Observations that connective tissue components such as fibronectin, collagen, tropoelastin, and elastinderived peptides have chemotactic activity for fibroblasts in vitro are of interest, but at present the meaning of such findings remains unclear. It will be important to develop a variety of data to give perspective to this new information. The need for detaching fibroblasts with trypsin or EDTA before testing them for chemotaxis raises questions about the mechanisms involved in vivo in releasing fibroblasts from their attachments. Further, because several components of the matrix express chemotactic activity for fibroblasts in vitro, it is not evident which component(s) exerts a biologically relevant directive force in normal and pathologic conditions. The role of elastin-derived pep-

\footnotetext{
${ }^{2}$ Senior, R. M., G. L. Griffin, and D. W. Urry. Unpublished observations.
}

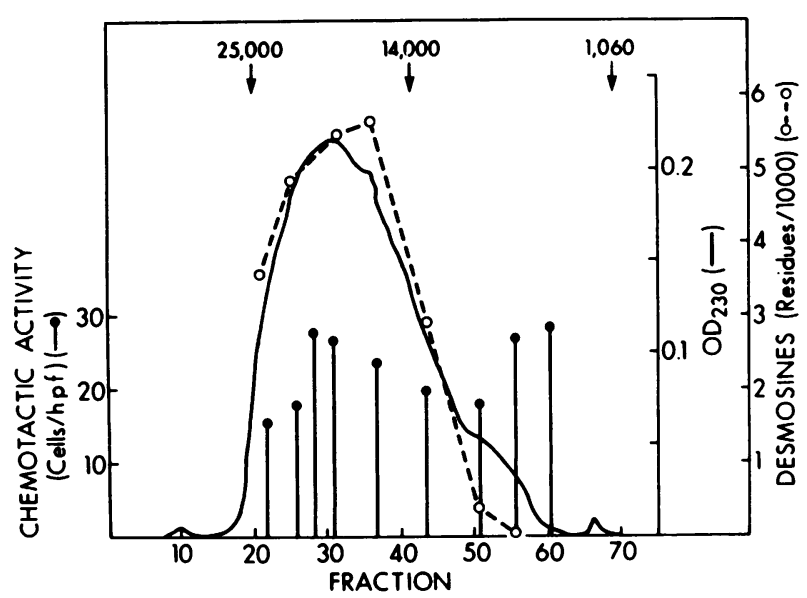

Figure 4 Relationships between the chemotactic activity for ligament fibroblasts, gel filtration profile, and desmosine content of bovine ligament elastin that has been digested with pancreatic elastase. Column standards: chymotrypsinogen $(25,000)$, lysozyme $(14,000)$, and bradykinin $(1,060)$.

tides as chemoattractants for fibroblasts, for example, might be minor because fibronectin, which is ubiquitous and highly susceptible to proteolytic degradation into fragments with chemotactic activity for fibroblasts (8), would likely be degraded simultaneously with elastin.

Recently, it has been observed that alveolar macrophages from patients with idiopathic pulmonary fibrosis produce and release much more fibronectin than alveolar macrophages from normal subjects, suggesting a possible pathogenetic role for fibronectin in this disease (24). However, the finding that fibroblasts release chemotactic activity for neutrophils and monocytes (25), which in turn can release proteinases that degrade connective tissue, emphasizes the complexity of the mechanisms that may be involved in disorders such as idiopathic pulmonary fibrosis where pathologic changes consist of admixtures of inflammation and fibrosis (26).

\section{ACKNOWLEDGMENT}

The authors thank Dr. John A. McDonald for helpful suggestions.

This work was supported by U. S. Public Health Service grants HL 16118 (Dr. Senior and Dr. Mecham), and HL 26499 (Dr. Mecham). Dr. Mecham is an Established Investigator of the American Heart Association, with funds contributed in part by the St. Louis Heart Association, Missouri Affiliate.

\section{REFERENCES}

1. Postlethwaite, A. E., R. Snyderman, and A. H. Kang. 1976. The chemotactic attraction of human fibroblasts 
to a lymphocyte-derived factor. J. Exp. Med. 144: 11881203.

2. Postlethwaite, A. E., J. M. Seyer, and A. H. Kang. 1978. Chemotactic attraction of human fibroblasts to type I, II, and III collagens and collagen-derived peptides. Proc. Natl. Acad. Sci. USA. 75: 871-875.

3. Chiang, T. M., A. E. Postlethwaite, E. H. Beachey, J. M. Seyer, and A. H. Kang. 1978. Binding of chemotactic collagen-derived peptides to fibroblasts. The relationship to fibroblast chemotaxis. J. Clin. Invest. 62: 916-922.

4. Postlethwaite, A. E., R. Snyderman, and A. H. Kang. 1979. Generation of a fibroblast chemotactic factor in serum by activation of complement. J. Clin. Invest. 64: 1379-1385.

5. Gauss-Müller, V., H. K. Kleinman, G. R. Martin, and E. Schiffman. 1980. Role of attachment factors and attractants in fibroblast chemotaxis. J. Lab. Clin. Med. 96: 1071-1080.

6. Postlethwaite, A. E., J. Keski-Oja, G. Balian, and A. H. Kang. 1981. Induction of fibroblast chemotaxis by fibronectin: localization of the chemotactic region to a 140,000-molecular weight non-gelatin-binding fragment. J. Exp. Med. 153: 494-499.

7. Tsukamoto, Y., W. E. Helsel, and S. M. Wahl. 1981. Macrophage production of fibronectin, a chemoattractant for fibroblasts. J. Immunol. 127: 673-678.

8. Seppa, H. E. J., K. M. Yamada, S. T. Seppa, M. H. Silver, H. K. Kleinman, and E. Schiffman. 1981. The cell binding fragment of fibronectin is chemotactic for fibroblasts. Cell Biol. Int. Rep. 5: 813-819.

9. Mecham, R. P., G. Lange, J. Madaras, and B. Starcher. 1981. Elastin synthesis by ligamentum nuchae fibroblasts: effects of culture conditions and extracellular matrix on elastin production. J. Cell Biol. 90: 332-338.

10. Mecham, R. P., and J. A. Foster. 1977. Trypsin-like neutral protease associated with soluble elastin. Biochemistry. 16: 3825-3831.

11. Whiting, A. H., B. C. Sykes, and S. M. Partridge. 1974. Isolation of salt-soluble elastin from ligamentum nuchae of copper-deficient calf. Biochem. J. 141: 573-575.

12. Senior, R. M., G. L. Griffin, and R.P. Mecham. 1980. Chemotactic activity of elastin-derived peptides. J. Clin. Invest. 66: 859-862.

13. Bielefeld, D. R., R. M. Senior, and S-Y. Yu. 1975. A new method for determination of elastolytic activity using ${ }^{14} \mathrm{C}$-labeled elastin and its application to leukocytic elastase. Biochem. Biophys. Res. Commun. 67: 1553-1559.

14. Mecham, R. P., and G. Lange. 1982. Antigenicity of elastin. Characterization of major antigenic determinants on purified, insoluble elastin. Biochemistry. 21: 669-673.
15. McDonald, J. A., and D. G. Kelley. 1980. Degradation of fibronectin by human leukocyte elastase: release of biologically active fragments. J. Biol. Chem. 255: 88488858.

16. Neuman, R. E., and S. K. Ainsworth. 1980. A simplified procedure for the assay of leukocyte chemotaxis. J. Reticuloendothel. Soc. 28: 305-312.

17. Campbell, P. B. 1977. An improved method for the in vitro evaluation of monocyte leukotaxis. J. Lab. Clin. Med. 90: 381-388.

18. Mazia, D., G. Schatten, and W. Sale. 1975. Adhesion of cells to surfaces coated with polylysine. J. Cell Biol. 66: 198-200.

19. Hunninghake, G. W., J. M. Davidson, S. Rennard, S. Szapiel, J. E. Gadek, and R. G. Crystal. 1981. Elastin fragments attract macrophage precursors to diseased sites in pulmonary emphysema. Science (Wash., DC). 212: 925-927.

20. Urry, D. W., and M. M. Long. 1976. Conformations of the repeat peptides of elastin in solution: an application of proton and carbon-13 magnetic resonance to the determination of polypeptide secondary structure. CRC Crit. Rev. Biochem. 4: 1-45.

21. Urry, D. W., M. A. Khaled, V. Renugopalakrishnan, and R. S. Rapaka. 1978. Proton magnetic resonance and conformational energy calculations of repeat peptides of tropoelastin: the hexapeptide. J. Am. Chem. Soc. 100: 696-705.

22. Cook, W. J., H. Einspahr, T. L. Trapane, D. W. Urry, and C. E. Bugg. 1980. Crystal structure and conformation of the cyclic trimer of a repeat pentapeptide of elastin, cyclo-(L-valyl-L-prolylglycyl-L-valylglycyl) $)_{3} . J$. Am. Chem. Soc. 102: 5502-5505.

23. Urry, D. W., T. L. Trapane, H. Sugano, and K. U. Prasad. 1981. Sequential polypeptides of elastin: cyclic conformational correlates of the linear polypentapeptide. J. Am. Chem. Soc. 103: 2080-2089.

24. Rennard, S. I., G. W. Hunninghake, P. B. Bitterman, and R. G. Crystal. 1981. Production of fibronectin by the human alveolar macrophage: mechanism for the recruitment of fibroblasts to sites of tissue injury in interstitial lung diseases. Proc. Natl. Acad. Sci. USA. 78: 7147-7151.

25. Sobel, J. D., and J. I. Gallin. 1979. Polymorphonuclear leukocyte and monocyte chemoattractants produced by human fibroblasts. J. Clin. Invest. 63: 609-618.

26. Fulmer, J. D., and R. G. Crystal. 1979. Interstitial lung disease. In Current Pulmonology. D. H. Simmons, editor. Houghton Mifflin Company, Boston, MA. 1: 1-65. 